\title{
Intelligent drug design come of age: STI571 as the start a of a new era in cancer research and treatment
}

The discovery of the genes responsible for the onset and progression of cancer in the 80's was perceived as the beginning of a new era in cancer research and treatment. As soon as the first oncogenes and tumor suppressor genes were identified it was clear that they were masters in the management of the cell response to extracellular stimuli. Aberrant signaling mechanisms and the deregulated cellular clock were responsible for the appearance of cancer. Thus, signal transduction pathways and the cell cycle became the focus of most of the studies that aimed to revert the oncogenic phenotype. The rational behind was relatively simple and made many to believe that a cure for cancer was soon to be achieved. If cancer cells arise by mutations on specific genes that alter the enzymatic activity of normal proteins involved in signaling pathways and cell cycle regulation, specific inhibition of these elements would interfere with cancer progression. From then, many different approaches have been designed and attempted, almost as many as different types of tumors have been identified. Also, many disappointments have been harvested ever since.

But constancy pays off, and twenty years later, the first real success of drug design against cancer seems to have arrived as the first clinical trials on the tyrosine kinase inhibitor imatinib mesylate (Glivec trade mark, Novartis Pharmaceuticals Corp, East Hanover, NJ; formerly STI571) are released $^{1-5}$. This is good news for cancer researchers and clinicians that will return from desperation to hope, since previous efforts on similar themes to that of STI571 were largely unsuccessful. Take, if you wish, the inhibitors of the Farnesyl Tranferase as an example for the demonstration of such a disappointment. Originally Farnesyl Tranferase Inhibitors (FTIs) were thought as specific drugs that would prevent the activation of the Ras protein by

Rev Oncología 2001; 3: 229-230 interfering with its localization to the plasma membrane. Ras is the most important oncogene involved in human cancer. Therefore its specific inhibition would imply major breakthrough in cancer therapy. However, FTIs proved to be non-specific for Ras proteins. Furthermore, even though they showed some antitumoral activity in preclinical studies, its target seems to be independent on the status of the Ras protein ${ }^{6}$. But FTIs is not the only case and many potential candidates to become specific drugs for cancer treatment have failed to be effective and never reached the clinic.

STI571 is a 2-phenylaminopyridine derivative that functions as an ATP competitive inhibitor for a small set of tyrosine kinases. It was developed as a specific inhibitor for the PDGFR kinase, but shows also activity against other kinases, most remarkably the $\mathrm{Abl}$, and Kit kinases. Thus, any tumor where PDGFR, $\mathrm{Abl}$ or Kit kinases are key players, were potential candidates for STI571 treatment. As with many other drugs designed similarly, STI571 proved to be effective in preclinical studies against cells derived from patients with Chronic Myeloid Leukemia (CML) ${ }^{7-}$ ', a disease clearly correlated with the constitutive activation of the Bcr-Abl kinase ${ }^{10-12}$. Clinical studies demonstrate also its efficacy and safety on patients with $\mathrm{CML}^{1,2}$. Furthermore, other tumors where the Kit tyrosine kinase plays a role are also susceptible for treatment with STI571 with promising results ${ }^{3,4}$. These first reports are impressive in many senses. First, it implies that intelligent drug design against cancer is not a promise anymore, but a dream come true. It also opens the path to an obvious observation: cancers must be dealt according to their molecular biology fingerprint. What is important for an appropriate clinical management is the molecular alterations involved in each case, not the origin or the cellular phenotype of the tumor. Molecular oncology and clinical oncology are not separate entities, but the two faces of the same coin. This is also an important lesson to be learnt. 
Finally, the STI571 case is the milestone that announces a must for the oncology world: to defeat each type of cancer, a more profound knowledge on the molecular alterations involved is needed. This will allow designing the most appropriate strategy for each kind of tumor, dramatically increasing the changes for success. It is most promising to learn that over 400 drugs designed by a similar method to that of STI571, are under investigation as new cancer therapies.

A new era full of excitement on cancer research just started, as we are collecting results of many merging specialties and expertise. In this pot not only molecular biology is an ingredient, from which we are learning about the complexity and functionality of the human genome and the way cells are controlled. Also the use of new materials and equipment is allowing the development of wonderful machines that can easily analyze expression profiles and arrays, tumor responses to treatment, cancer similarities and differences, and many other important issues.

Biochemistry, medicinal chemistry, structural biology, immunology and several other specialties are also important necessary ingredients for the design and development of new strategies and drugs against cancer. It will take time and many attempts, but sooner or later the key for each type of tumor will be definitively discovered.

STI571 is the leading example of what can be achieved from the marriage between experimental and clinical oncology. A large number of issues need still to be addressed. Among the most important, are several key questions. Is there any long term side effects that might be associated with the drug? Is there generation of resistance after STI571 treatment? Is this drug a definitive cure for at least some tumors? Do tumors relapse? Why cells from CML die after STI571 treatment? Time will cure our impatience and will provide appropriate answers to all these questions and many more. But whatever the results will be, the proof of principle has been provided. We have recovered our hope and filled up the depleted deposit of the energy needed to continue this difficult and important task: to learn much more on the molecular biology of all types of tumors. The rest will arrive soon after.

\section{Juan Carlos Lacal} Executive Editor

\section{References}

1. Druker BJ, Sawywers CL, Kantarjian $\mathrm{H}$, et al. Activity of specific inhibitor of the BCr-Abl tyrosine kinase in the blast crisis of chronic myeloid leukemia and acute lymphoblastic leukemia with the Philadelphia chromosome. N Engl J Med 2001; 344: 1.038-1.042.

2. Druker BJ, Talpaz M, Resta DJ, et al. Efficacy and safety of a specific inhibitor of the Bcr-Abl tyrosine $\mathrm{ki}$ nase in chronic myeloid leukemia. N Engl J Med 2001; 344: 1.031-1.037.

3. Joensuu H, Roberts PJ, Sarlomo-Rikala M, et al. Effect of the tyrosine kinase inhibitor STI571 in apatient with a metastatic gastrointestinal stromal tumor. N Engl J Med 2001; 344: 1.052-1.056.

4. Van Oosterom AT, Judson I, Verweij J, et al. STI571, an active drug in metastatic gastro intestinal stromal tumors (GIST), an EORTC phase I study. Proc Am SoC Clin Oncol 2001; 20: 1a.

5. Durker BJ, Tamura S, Buchdunger $E$, et al. Effects of a selective inibitor of teh Abl tyrosine kinase on growth of Bcr-Abl positive cells. Nat Med 1996; 2: 561-566.

6. Aznar S, Lacal JC. Searching new targets for anticancer drug design: the families of Ras and Rho GTPases and their effectors. Prog Nucleic Acid Res Mol Biol 2001; 67: 193-234.

7. Gambacorti-Passerini C, Le Coutre P. Mologni L, et al. Inhibition of the Abl kinase activity blocks the proliferation of $\mathrm{BCR} / \mathrm{ABL}+$ leukemic cells and induces apoptosis. Blood Cells Mol Dis 1997; 23: 380-394.

8. Deininger MW, Goldman MJ, Lydon N, Melo JV. The tyrosine kinase inhibitor CGP57148B selectively inhibits the growth of BCR-ABL-positive cells. Blood 1997; 